\title{
Control of bursting activity by modulation of ionic currents Tatiana Malashchenko ${ }^{1}$, William Barnett ${ }^{1}$, Oleksandr Burylko ${ }^{2}$ and Gennady Cymbalyuk*1
}

Address: ${ }^{1}$ Department of Physics and Astronomy, Georgia State University, Atlanta, GA 30303, USA and 2Institute of Mathematics, NAS of Ukraine, 3 Tereshchenkivska str., Kiev, Ukraine 01601

Email: Gennady Cymbalyuk* - gcym@phy-astr.gsu.edu

* Corresponding author

from Eighteenth Annual Computational Neuroscience Meeting: CNS*2009

Berlin, Germany. 18-23 July 2009

Published: 13 July 2009

BMC Neuroscience 2009, I0(Suppl I):P27 doi:I0.I |86/I47|-2202-I0-SI-P27

This abstract is available from: http://www.biomedcentral.com/I47I-2202/I0/SI/P27

(c) 2009 Malashchenko et al; licensee BioMed Central Ltd.

Our study is focused on modulation of dynamics of single leech heart interneurons (HNs). We consider two models of HNs representing these neurons under two different pharmacological treatments: (1) blocking of $\mathrm{Ca}^{2+}$ currents and inhibitory coupling with the $\mathrm{Ca}^{2+}$-containing saline and partial blocking of $\mathrm{K}^{+}$currents; (2) decoupling HNs with bicuculline. In (1), an HN demonstrates slow plateau-like oscillations $[1,2]$. In (2), an HN demonstrates endogenously bursting activity [3]. We analyze how the interburst interval and burst duration could be controlled by manipulating hyperpolarization-activated current, $I_{h^{\prime}}$ and persistent $\mathrm{Na}^{+}$current, $I_{P}$, namely by variation of their conductances and the half-activation voltages, $V_{1 / 2}$. For example, burst duration increases greatly from $1.7 \mathrm{~s}$ to 8.9 $\mathrm{s}$ as $V_{h, 1 / 2}$ increased from $-30 \mathrm{mV}$ to $4 \mathrm{mV}$. The interburst interval grows from $0.6 \mathrm{~s}$ to $125 \mathrm{~s}$ as the $V_{h, 1 / 2}$ decreases from $4[\mathrm{mV}]$ to $-56[\mathrm{mV}]$ in accordance with a saddlenode bifurcation. In (2), we similarly show that the variation of $V_{h, 1 / 2}$ could be a target for modulation of the bursting. In both cases, we show co-existence of bursting and silence. Interestingly, the co-existence is sensitive to $g_{h}$ (and to maximal conductance of fast $\mathrm{Ca}^{2+}$ current, $g_{\mathrm{CaF}}$ too in (2)) and is not sensitive to the maximal conductances of other currents. In (1), if $g_{h}$ is increased from $4 \mathrm{nS}$ to 8 $\mathrm{nS}$, the bistability is then observed in an almost five-fold larger range of the leak conductance values, $g_{\text {leak }}$. In (2), if either $g_{h}$ is changed from $4 \mathrm{nS}$ to $8 \mathrm{nS}$ or $g_{\mathrm{CaF}}$ is changed from $5 \mathrm{nS}$ to $0 \mathrm{nS}$, the bistability is observed in an almost two-fold larger range of $g_{\text {leak }}$. If the bistability is an indication of a dysfunctional dynamics, this observation describes a new, potentially pathological role of overexpression of $I_{h}$ and $I_{\mathrm{CaF}}$.

\section{Acknowledgements}

This work is supported by NSF grant PHY-0750456.

\section{References}

I. Angstadt JD, Friesen WO: Synchronized oscillatory activity in leech neurons induced by calcium channel blockers. J Neurophysiol 1991, 66:1858-1873.

2. Opdyke CA, Calabrese RL: A persistent sodium current contributes to oscillatory activity in heart interneurons of the medicinal leech. / Comp Physiol 1994, I 75:78I-789.

3. Cymbalyuk GS, Gaudry Q, Masino MA, Calabrese RL: Bursting in leech heart interneurons: cell-autonomous and networkbased mechanisms. J Neurosci 2002, 22:10580-10592. 